\title{
THE INTERNAL ANATOMY OF SPHYRION LUIIPI (KRØYER, 1845) BASSETT-SMITH 1899, A COPEPOD PARASITIC ON OCEAN PERCH
}

\author{
HAIG H. NAJARIAN \\ Department of Zoology, University of Michigan, Ann Arbor"
}

TWENTY-SEVEN FIGURES

\section{INTRODUCTION}

From a parasitological viewpoint, the subclass Copepoda is an interesting and important group both in regard to serving as intermediate hosts for numerous helminths and as true parasites of fish. Although many papers have been written on the anatomy of parasitic copepods, relatively little attention has been given to the internal anatomy, especially the histology of the internal organs. This study deals with the internal anatomical and histological features of the female of Sphyrion lumpi (Krøyer, 1845) Bassett-Smith 1899, a copepod parasitic on ocean perch. This copepod is one of the most extremely modified members of the family Sphyriidae Wilson 1919.

The host, Sebastes marinus (Limnaeus) is commonly known to east coast fishermen as redfish or rosefish (figs. 1 and 2). They refer to the attached copepods as "buttons." The center at which large quantities of redfish are filleted is Gloucester, Massachusetts. The fish are then shipped to midwestern consumers as ocean perch fillets. Studies on S. lumpi

${ }^{1} \mathrm{~A}$ large part of this paper is a portion of a thesis submitted in partial fulfillment of the requirements for the degree of Master of Arts, Boston University, 1949. Sincere acknowledgment is extended to Dr. Arthur G. Humes, under whom the study was made. 
seem of particular importance not only because of the growing redfish industry, which has amounted to an annual catch of $50,000,000$ pounds in past years (Herrington, '39), but also because of the extreme modifications of the copepod in relation to its parasitic existence.

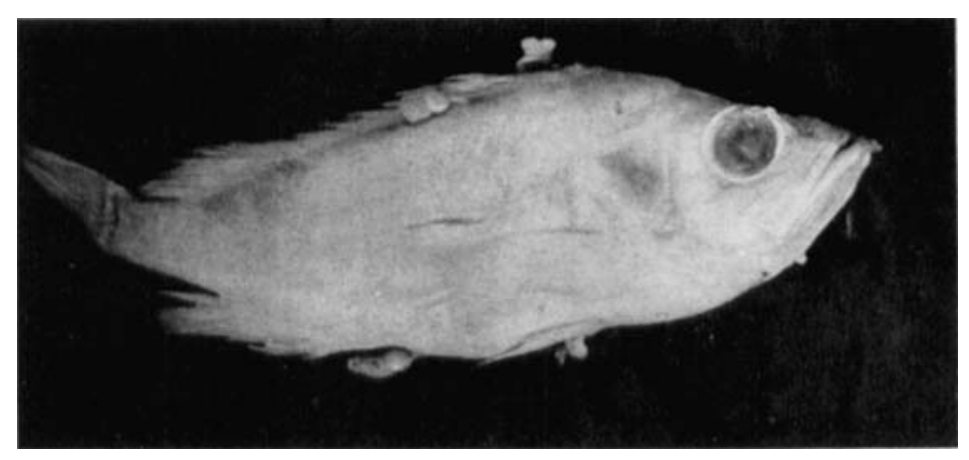

Fig. 1 Photograph of the right side of the ocean perch, Sebastes marinus (Linnaeus), showing attachment of female specimens of the parasitic copepod, Sphyrion lumpi (Kroyer) Bassett-Smith 1899.

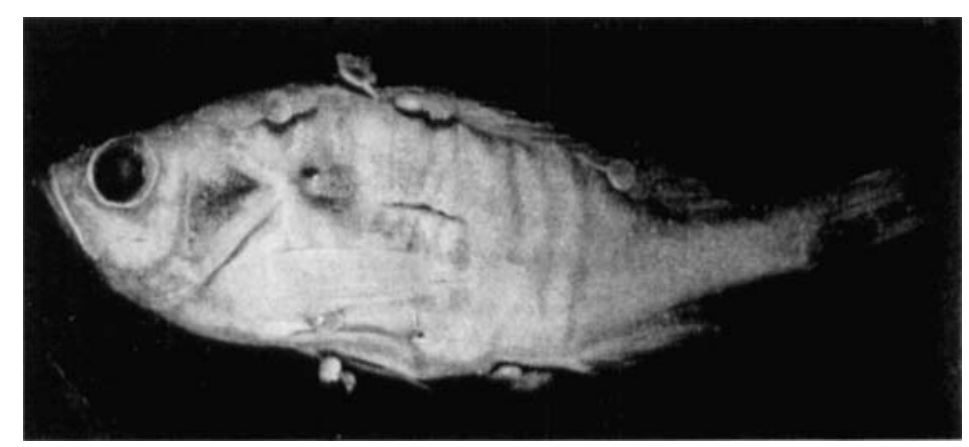

Fig. 2 Photograph of the left side of the same specimen.

Wilson ('19) and Nigrelli and Firth ('39) have described the anatomical features of $S$. lumpi. The latter paper deals mainly with pathology and gives one figure of a section through the encapsulated cephalothorax. Wilson's description is accompanied by two figures of the internal anatomy, but does not deal with the histology of the internal organs. 


\section{MATERIALS AND METHOIS}

The specimens used in this study were taken from redfish brought to the Boston Fish Pier during the month of October, 1948. The copepods were collected at random during the unloading of the fish. Because the fish were taken away immediately by the buyer, it was not possible to record an incidence of infection. However, the infected redfish examined had an average of 2.6 visible parasites. One specimen harbored 9 adult female $S$. lumpi. No males were observed. According to the fishermen at the pier, the examined redfish were taken from the vicinity of George's Bank, a heary redfish area located at $41-42^{\circ}$ north latitude and $66-$ $69^{\circ}$ west longitude.

Although some of the specimens were cut out with the attached host flesh, most of them were excised directly from the fish. This was done by making an incision with finepointed scissors along the lateral cephalothorax expansions and then pulling gently on the parasite, whereupon it usually came out very easily. The copepods were placed in vials containing three different fixatives, viz., Bouin's, Zenker's, and $10 \%$ formalin. In the laboratory, the specimens were treated with boiling sodium hypochlorite, in order to soften the sclerotized exoskeleton, and were cut into several pieces before dehydration and infiltration. Care was taken to keep the colrect orientation for each segment of the parasite. The paraffin method was used for embedding, and sections were cut at $8 \mu$. The following stains were used : Harris' hematoxylin, iron hematoxylin, Mallory's triple; van Gieson's and fast green as counter stains.

\section{OBSERVATIONS}

Bodly wall. The body wall is composed of two distinct layers (fig. 12). The outer layer is thick, acellular, transparent, and covers the entire body. It is generally the same thickness throughout, except in the neck and anterior part of the trunk, where it is somewhat thicker. From gross observation, it appears to be a single solid layer, but is actually made up of 
several lamellae. The entire layer is sclerotized and stains heavily.

The inner body wall layer is composed of several layers of columnar cells with large nuclei concentrated at the bases of the cells. Toward the medial side, the cells become extremely narrow and are continuous with fiber-like processes which extend into the parenchymatous tissue of the internal cavities. This inner layer lines the entire inner surface of the copepod but does not extend into the ovisacs, which do not have a cellular lining of any sort.

Parenchyma. Parenchymatous tissue is found in all the internal body cavities where it probably serves as padding for the internal organs. It is made up of oval cells with long irregular processes and contains much intercellular space. The entire tissue has a mesh-like arrangement (fig. 15).

Lateral expansions of the cephalothorax. The internal cavities of the lateral expansions of the cephalothorax are made up of irregular oval bundles of closely-packed spongy material. Each is surrounded by a thick dark-staining membrane. No nuclei are present. Under low magnification the spongy material in each bundle appears tightly packed, but higher magnification shows many interstices. Each lateral expansion has one large bundle at the center and smaller ones toward the periphery (fig. 25).

Musculature. The musculature is made up of striated fibers, is fairly well developed in young forms, but is less noticeable in mature specimens. It is of two general types: dorso-ventral muscles and longitudinal muscles (fig. 3).

The dorso-ventral muscles are muscle bands which are attached to the outer body wall and extend from both the dorsal and ventral surfaces into the body cavity. In the trunk region, these muscles extend between the coils of the oviducts and it is possible that their contractions are concerned with movement of the egg's along the oviducts. Their outer attachments cause pits to appear on both the dorsal and ventral surfaces of the trunk. 
A modification of the dorso-ventral muscles are bands which run from the dorso-lateral portion of the head to the region of the maxillipeds. Another modification of these muscles is found in the region of the rectum, where several bands run from the rectum to both the dorsal and ventral surfaces of the copepod. These rectal muscle fibers are especially well developed in young specimens. It is possible that the contractions of these muscles aid in respiration by causing water to be sucked into the rectal chamber.

The longitudinal muscles consist of bands which run lengthwise immediately beneath the dorsal and ventral surfaces of the body. These bands originate in the region where the oblique dorso-ventral muscles extend to the maxillipeds. There are 4 dorsal bands and 4 ventral bands. The dorsal bands are close together anteriorly, but are separate in the mid-trunk region; they meet again to end abruptly just above the rectum. The ventral bands are separate the entire distance posteriorly, except just above the rectum where they come together and end abruptly.

Both the dorso-ventral and longitudinal muscles are made up of striated muscle fibers numbering 10-12 in the former and 16-18 in the latter. The fibers are cylindrical with numerous elongate nuclei along the outer margin of each fiber.

Circulation. Both Wilson ('15), in an examination of the parasitic copepods of the Lernaeopodidae, and el Salby ('33), in his study of the Chondracanthidae and Lernaeopodidae, found no evidence of circulatory organs or vessels. However, Wilson suggested that the body fluids may circulate by means of the peristaltic movements of the gut and the contractions of both the dorso-ventral and longitudinal muscles.

Sections of $S$. lumpi show this parasite to have a system of sinuses both dorsal and ventral to the intestinal tracts. These sinuses are irregularly arranged in the cephalothorax, but in the neck region show an arrangement of three small sinuses dorsal to the intestine and one large sinus which runs ventral to the gut. This arrangement continues to the trunk 
region, where the three dorsal sinuses are gradually blotted out by the enlargement of the dorsal intestinal processes, but since the ventral intestinal processes never reach the ventral body wall the ventral sinus keeps its identity throughout the trunk region. Each sinus is surrounded by a muscular membrane (fig. 27). The ventral sinus becomes smaller and ends at a point just before the attachment of the rectal muscles.

Muscular contraction of the gut would seem to exert sufficient force for circulation of body fluid through the sinuses and parenchyma. In addition, because the sinuses are surrounded by muscular membranes, they probably serve as conduction vessels and play a part in circulation.

Excretory glands. The excretory organs consist of a pair of glands in the dorsal part of the cephalothorax in the region of the esophagus. Fach gland consists of irregular lobes and is made up of two distinct layers. The outer layer or cortex consists of a network of cells containing large oval nuclei. The inner layer or medulla is made up of a non-cellular material which stains lighter than the cortex and sends out radiating arms to parts of the latter (fig. 9). Sections show deep-staining granules grouped together in the vicinity of the radiating arms. A duct arises from the ventral surface of the gland and proceeds in the direction of the maxillipeds. It consists of thin, muscular material and contains numerous excretory granules of the same type found around the radiating arms of the medulla.

Nervous system. Wilson ('19) described sub- and supraesophageal ganglia in the adult females of the Sphyriidae. Since no special techniques were used in the present study, neither ganglia nor nerves were observed.

Means of respiration. Since immature forms of $S$. lumpi show several bands of rectal muscles, it is possible that anal respiration occurs in these young forms. However, as the copepod matures, the rectal muscles become less prominent and during this time grape-like processes arise from the posterior end of the body. These are dichotomously branched. Each bunch comes off a main shaft and is made up of the 
two layers of the body wall and contains parenchyma (fig. 21). The inner body wall is made of a layer of cuboidal cells. The internal cavities of the processes are filled with parenchyma of the type found in the trunk region, but with more cells per unit area. Because the posterior processes hang freely in the water during the attachment of the parasite, and also because they become profusely branched at a time when anal respiration is being abandoned, it is very probable that the greater part of respiration in the adult females takes place by means of these structures.

Digestive system. The gut of S. lumpi shows several interesting features. The mouth tube is short and is followed by a narrow esophagus which leads abruptly to an enlarged stomach. In the posterior portion of the cephalothorax, the stomach gives off two small diverticula which are both lateral in position and in direct communication with the main lumen of the stomach. Since digestion probably begins in the stomach, these diverticula may serve to increase the digestive area. The stomach leads to the intestine which is very narrow at the beginning of the trunk region and runs close to the dorsal surface. The intestine becomes quadro-radiate in the posterior part of the neck and then widens immediately before entering the trunk.

It is in the trunk region that the gut exhibits its greatest modifications. Intestinal processes or diverticula begin as simple outpouchings of the gut and are arranged as 5 rows in the anterior part of the trunk. One row arises from the dorsal surface of the gut. A dorso-lateral row and a ventrolateral row arise on each side. Each row becomes longer posteriorly and the epithelium becomes extremely folded. The dorsal row eventually reaches the inner dorsal surface of the body wall in the posterior part of the trunk. The dorsolateral diverticula become branched but do not reach the body wall. They end in the surroundings of the dorso-ventral muscles and the coils of the oviducts. The ventro-lateral diverticula are also branched. They almost reach the ventral body wall and then curl toward the mid-line where their extremities 
come to lie partially under the ventral portion of the gut. All rows of diverticula become shorter and less branched before the intestine joints the rectum.

The rectum is short, barrel-shaped, and ends as the anus at the posterior end of the trunk.

(a) Mouth tube. The mouth tube has a single layer of columnar epithelium (fig. 23). The nuclei are very distinct and each contains a centrally located nucleolus. The entire tube is surrounded by a network of parenehyma which acts as padding and probably gives a certain amount of support to the tube. However, the parenchyma does not come into direct contact with the tube. This condition probably allows for greater movement.

(b) Esophagus. The esophagus is made up of an outer membrane, a middle muscular layer, and an inner epithelium whose cells are columnar and in places pseudostratified (fig. 14).

(c) Stomach. The diameter of the stomach is about twice that of the esophagus and is made up of an outer membrane, a middle muscular layer, and an inner epithelium with numerous folds. The epithelial cells are columnar, but along the folded portions appear stratified. The most distinguishing feature of the stomach is the large number of epithelial gland cells (fig. 26). These cells have dark-staining granules and are attached to the stomach epithelium, although many of them are found in the lumen.

(d) Intestine. The cells making up the intestinal epithelium are distinctly columnar with large nuclei generally located at the center of each cell. The outer membrane and middle muscular layer closely encircle the epithelium (fig. 14). The only part of the neck region in which digestion might take place is in the posterior portion, where portions of the intestinal epithelium are thrown into folds, giving the appearance of intra-epithelial glands.

(e) Intestinal processes. Each of the intestinal processes in the trunk region is made up of an outer membrane, a middle muscular layer and an inner columnar epithelium. All 
the folds and subdivisions of the processes are complete and involve all the layers of each process. The most noticeable feature of the trunk intestine is the large number of epithelial gland cells and the thousands of secretory granules located all over the epithelium and within the lumina of the processes (fig. 19). These granules stain a golden brown with Harris' hematoxylin and phloxine. The greater part of digestion undoubtedly takes place within this region.

(f) Rectum. The rectum is made up of the same layers as the other portions of the gut, but its epithelium contains numerous crypts whose cells appear stratified. The middle muscular layer sends out strands which interweave with the epithelium (fig. 10). This muscular infiltration and the attachment of the dorso-ventral muscles to the rectal wall seem to indicate a role in respiration.

In the posterior part of the rectum of some of the copepods, a clump of loose fecal material was observed filling half the lumen and containing many digestive granules of the type found in the intestinal processes. The entire fecal lump was ensheathed by a membrane which is apparently secreted by the rectal epithelium, as other sections showed it coming off the free end of the epithelium.

Reproductive system. The reproductive organs include paired ovaries, paired oviducts, paired cement glands, and what appears to be a seminal receptacle.

The ovaries are situated in the lateral portions of the anterior portion of the trunk and consist of rows or filaments of ova (fig. 3). The ovary tubules are coiled and enclosed within the parenchyma. Each ovary leads abruptly to a wide oviduct. The oviducts, containing large developing eggs, coil several times within the trunk and open as two pits just before the beginning of the ovisacs or egg-strings. The cement glands are paired, each lying in a posterio-lateral position of the trunk. They extend from behind the ovary to the end of the trunk. Each gland is shaped like a parenthesis mark, the ends pointing toward the mid-line of 
the copepod, and is made up of two distinct parts: an outer cellular layer, and an inner acellular layer.

From the posterior end of the trunk there is a tubular structure which runs ventral to the gut and ends blindly below the middle of the rectum. This structure may be a seminal receptacle, but since no spermatophores were observed, and since no connection could be traced to the oviducts, its exact nature remains uncertain.

(a) Ovary. The ovaries are string-like, convoluted tubes, each containing rows of ova. A section of a single tube shows from $6-8$ ova (fig. 18). Each ovum contains a large, distinet nucleus with granular chromatin, and a large nucleolus usually located at one end.

(b) Oviduct. The wall of the oviduct is made up of a single layer of muscular fibers with elongated nuclei. No epithelium is found lining the oviduct. Within it are found many large developing ova which contain many yolk granules, located toward the periphery of each egg, and numerous vacuoles toward the center (fig. 20).

There is much space between each developing egg and the oviduct wall. Sections through one convolution invariably contain only one egg. A single column of developing eggs in the oviduct would seem of advantage to the copepod, since a conglomeration of eggs would cause blockage, especially at the curved portions of the convolutions.

Associated with the mature ova in the posterior portions of the oviducts are the filament cells. These cells have been reported in association with developing eggs in a variety of copepod families, but no adequate explanation has been given in regard to their origin and function. El Salby ('33) stated that the origin of these cells is not from the ovaries because they take a different stain. Although he was dealing with copepods of a different family, sections of $S$. lumpi show the filament cells to stain the same as the ovaries, suggesting their possible development from the latter. Also, the fact that the wall of the oviduct is only a thin muscular layer 
which stains differently from the filament cells suggests that development from the oviducts is not likely.

(c) Cement gland. The tubular cement glands are made up of two distinct layers and are bordered on the lateral surface by a thin sclerotized layer (fig. 22). The outer layer is cellular and is thick at the edge, lying in the lateral part of the trunk, but it becomes narrow in the portion of the gland closer to the mid-line. It is made up of a homogeneous mass of dark-staining cells which are arranged in vertical rows extending to the mid-line. The outer layer has numerous vacuoles, especially along the inner surface. The entire inner surface of the outer layer is composed of a sheet of non-cellular material of the same type, making up the inner portion of the gland.

The inner portion of the gland is made up of acellular, lightstaining, laminated layers, arranged concentrically toward the periphery, but showing no definite arrangement toward the center. The layers making up this inner portion of the gland are probably given off during the developmental period, and the time prior to egg-laying, and constitute the cement substance which covers the egg's following fertilization and before storage in the external egg sacs.

(d) Ovisac or egg-string. The wall of the ovisac is composed of layers of acellular, circular, fibrous material. The outer portion consists of a dark-staining sclerotized layer (fig. 24). The middle portion of the wall consists of a series of alternating light- and dark-staining areas. The innermost layer is a dark-staining area. From several places along the inner surface of the inner layer strands of fibrous material are given off. These weave around the eggs is the ovisac and probably serve to prevent the eggs from crowding each other within the sac. There are 8-10 eggs in each cross-section of the sac. No larval stages were observed.

\section{STMMARY}

1. The female of the ocean perch parasitic copepod, $S p h y$ rion lumpi (Krøyer), is attached to its host, Sebastes marinus 
(Linnaeus), by host encapsulation of the parasite's cephalothorax.

2. Serial sections of specimens obtained from ocean perch brought to the Boston Fish Pier were studied.

3. The internal anatomical and histological features of the copepod are described.

\section{LITERATURE CITED}

Basseit-Smith, P. W. 1899 A systematic description of parasitic Copepoda. found on fislies, with an enumeration of the known species. Proc. Zool. Soc. Jundon, 438-507.

HRRRINGTON, W. C. 1939 Observations on the life history, occurrence and distribution of the redfsh parasite, Sphyrion lmmpi. Bureau of Fisheries, Special Scientific Report No. 5: 1-12.

KRøyer, H. 1845 Danmarks Fiske. Kjøbenhavn Trokt i S. Triers Offiein, 3: $517-519$.

Nigrfili, R. F., AND Frank E. FtrTh 1939 On Sphyrion lampi (Krqyer), a copepod parasitic on the redfish, Sebastes marinus (Linnaeus), with special reference to the host-parasite relationships. Zoologiea, $24: 1-9$.

EL SALBY, M. K. 1933 The internal morphology of several parasitic copepods. Proc. Zool. Soc. London, 861-878.

Wilsow, C. B. 1915 North American parasitic copepods bolonging to the Lernaeopodidae, with a revision of the entire family. Proc. U. S. Nat. Mus., 50: 565-729.

1919 North American parasitic copepods belonging to the new family Sphyriidae. Proc. U. S. Nat. Mus., 55: 549-604. 


\section{PLATES}




\section{PLA'TE 1}

EXPLANATION OF FIGURES

3 Reconstruction of the internal anatomy of the female of $S$. lumpi, semidiagrammatic, dorsal view. Only a portion of the ovisacs and a few units of the posterior processes are shown. The reproductive system has been pulled out on the right side and slightly enlarged.
A, Anus
B, Spongy bundle of cephalothorax
CG, Cement gland
D, Dorso-ventral muscles
DI, Dorso-intestinal process
DLI, Dorso-latero-intestinal process
E, Esophagus
EG, Exeretory gland
ES, Egg sae or egg string
I, Intestine

L, Longitudinal muscle band

MT, Mouth tube

O, Ovum

OV, Ovary

OVI, Oviduct

PP, Posterior process

R, Rectum

RM, Reetal muscles

S, Stomach

VLI, Ventro-latero-intestinal process 


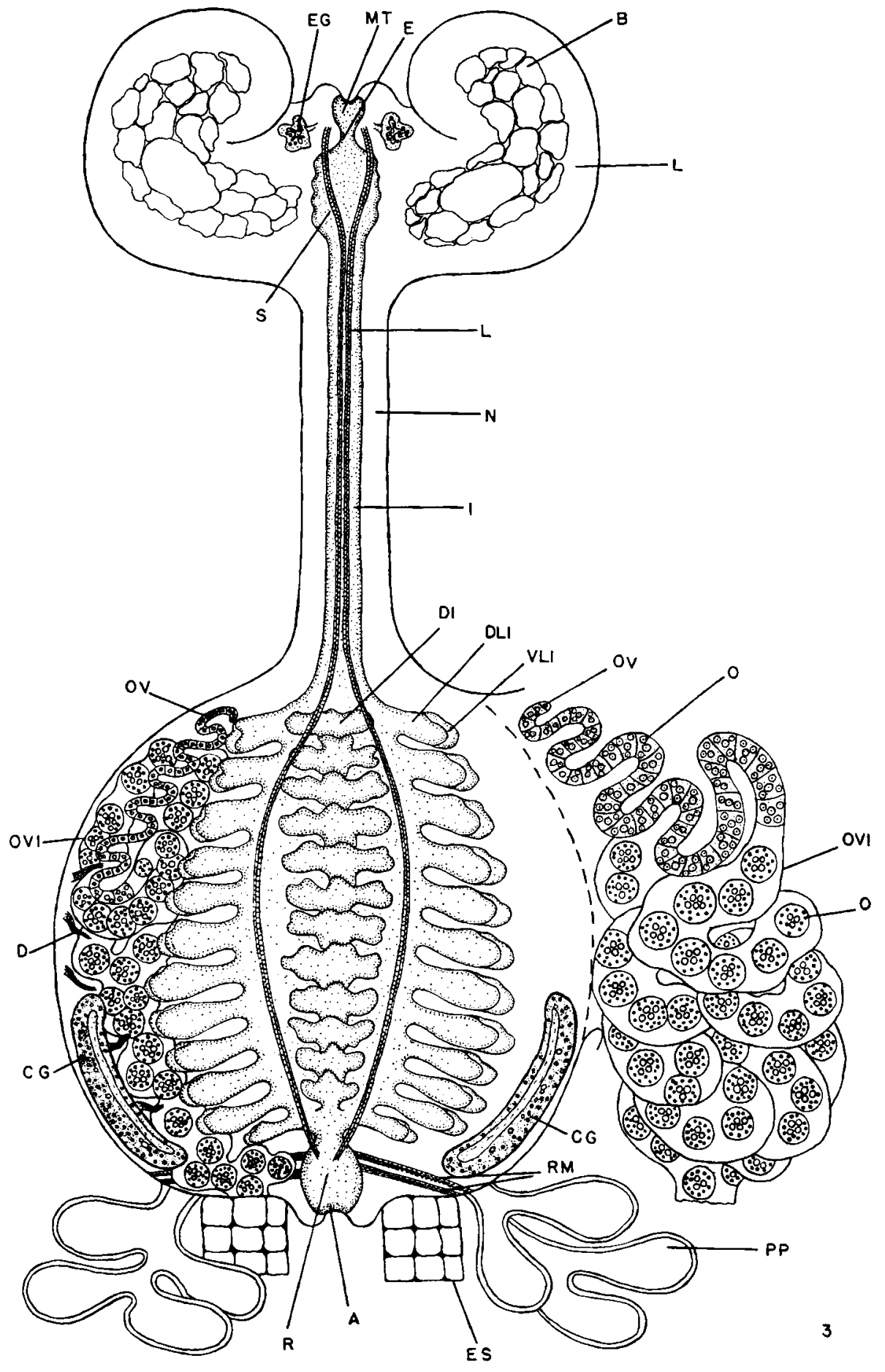




\section{PLATE 2}

EXPLANATION OF FIGURES

4 External features of S. lumpi.

5 Section through plane 1 in figure 4.

6 Section through plane 2 in figure 4 .

7 Section through plane 3 in figure 4 .

8 Section through plane 4 in figure 4 .

C, Cephalothorax

J), Dorsal sinus

UIP, Dorso-intestinal process

DL, Dorso-longitudinal muscles

DLI, Dorso-latero-intestinal process

])V, Dorso-ventral muscles

GC, Gland cell

I, Intestine

IB, Inner body wall

IC, Inner layer of cement gland

I, Latero-cephalothorax expansion

O, Orum

OB, Outer body wall

OC, Outer layer of cement gland
OT, Ovary

OV, Ovisac or egg string

OVI, Oriduct

$P$, Parenchyma

PP, Posterior process

S, Stomach

SG, Secretory granule

SI, Sinus

T, Trunk

VL, Ventro-longitudinal muscles

VII, Ventro-latero-intestinal process

VP, Ventro-intestinal process

VS, Ventral sinus 

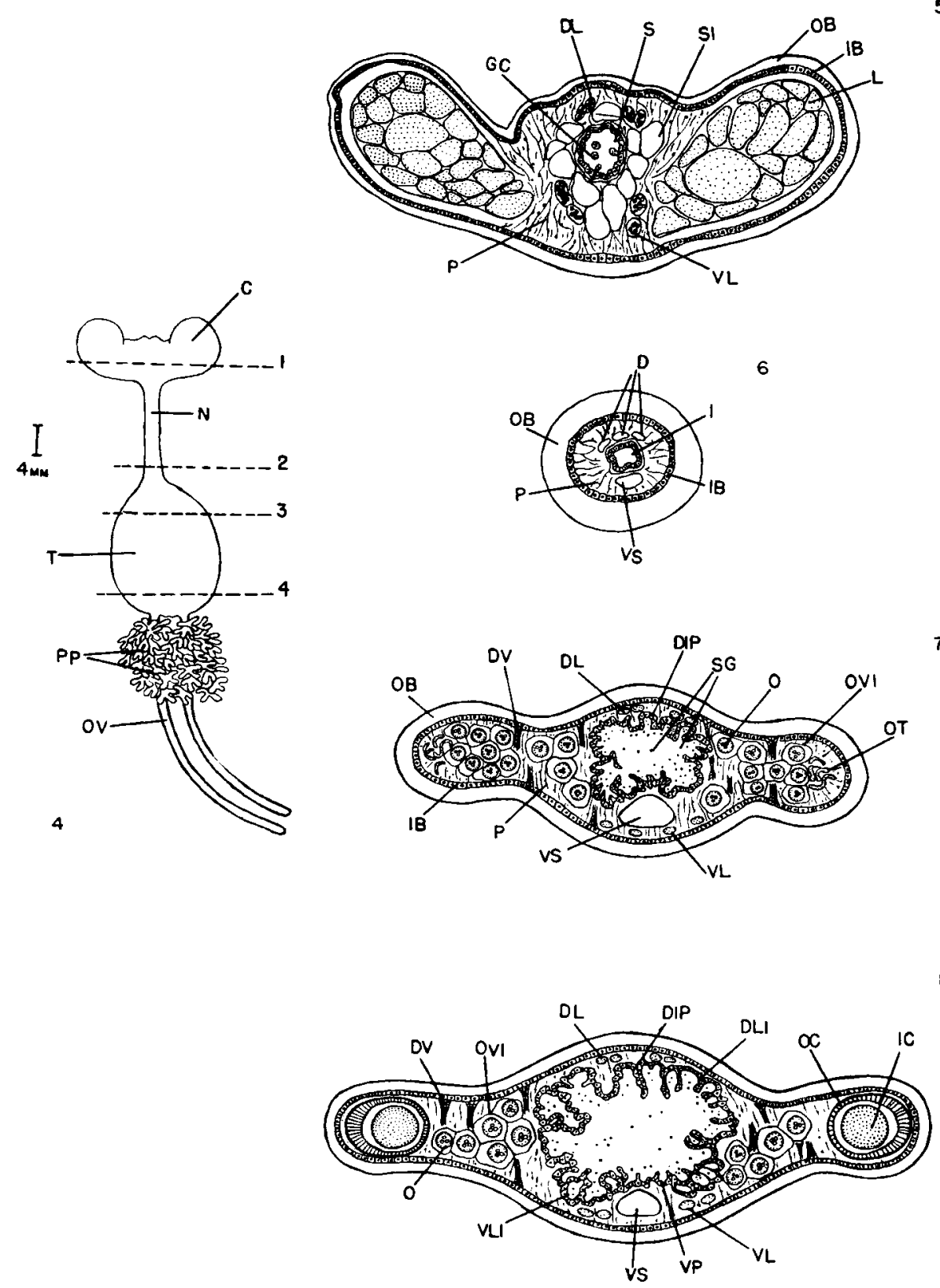


\section{PLATE 3}

\section{EXPLANATION OF FIGURES}

9 Cross section through exeretory gland. Scale B.

10 Portion of cross section through rectum. Scale B.

11 Longitudinal section through two muscle fibers. Scale C.

12 Portion of cross section through body wall. Seale $\mathrm{C}$.

13 Cross section of a few musele fibers. Scale C.

14 Cross section through esophagus. Scale $\mathrm{C}$.

15 Cross section through parenchyma. Seale C.

16 Longitudinal section through ovary tubule. Seale $\mathrm{C}$.

17 Cross section through intestine of neck region. Seale B.

18 Cross section through ovary tubule. Seale C.

19 Portion of cross section through intestinal processes. Scale B.

CR, Crypt of epithelium

$D$, Exeretory gland duet

EEP, Esophagus epithelium

EG, Exeretory granule

EM, Medulla of excretory gland

EP, Epithelium of inner body wall

G, Granule

GN, Granulated nucleus

IEP, Intestinal epithelium

IOU, Cortex of exeretory gland

MI, Middle muscular laver

MS, Muscle fiber
MU, Muscular duct wall

$\mathrm{N}$, Nucleus

NC, Nucleolus

o, Ovum

OU, Outer membrane

OUB, Outer body wall

$P$, Parenchyma

REP, Rectal epithelium

$\mathbf{s}$, Sinus

SG, Secretory granule

SGC, Secretory gland cell 

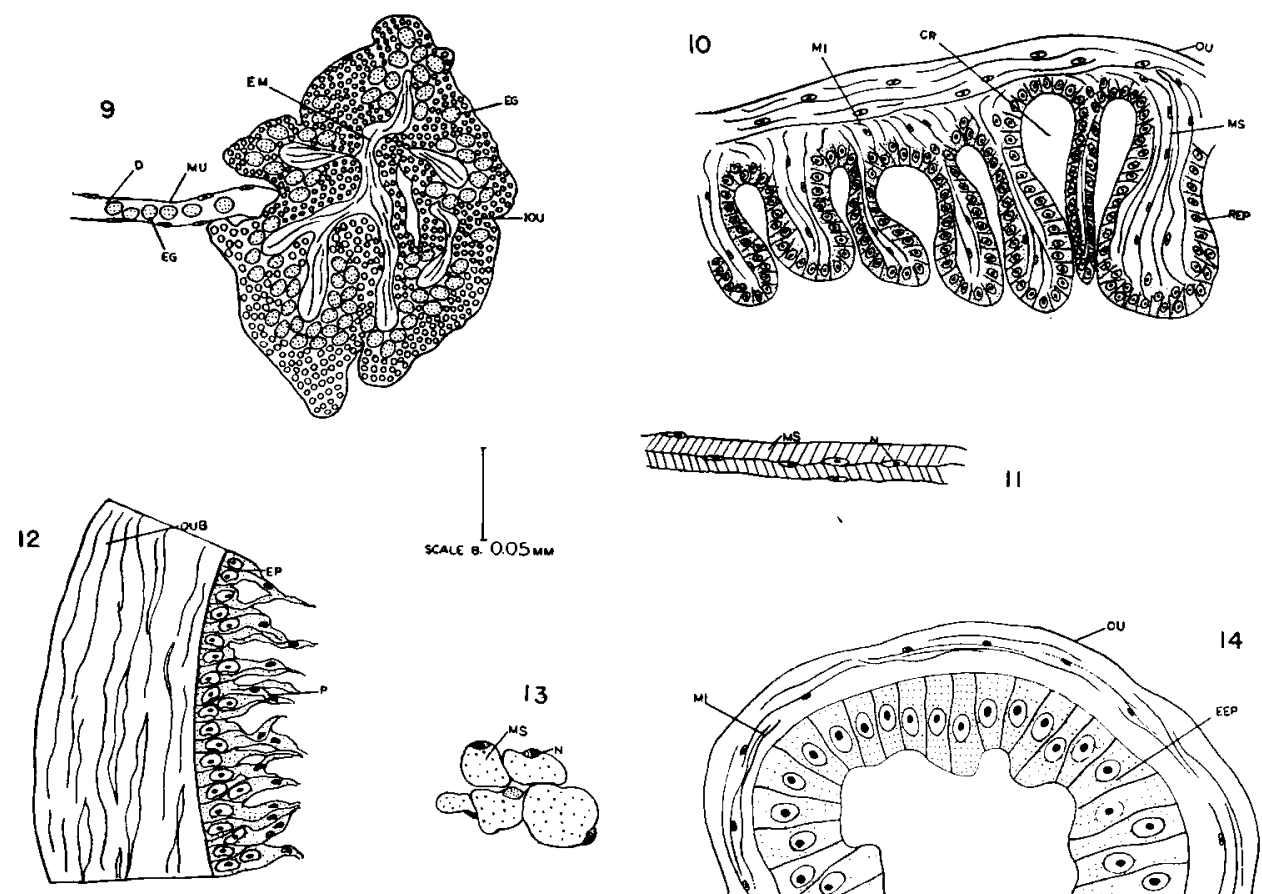

$\prod_{x a s e n}$

171
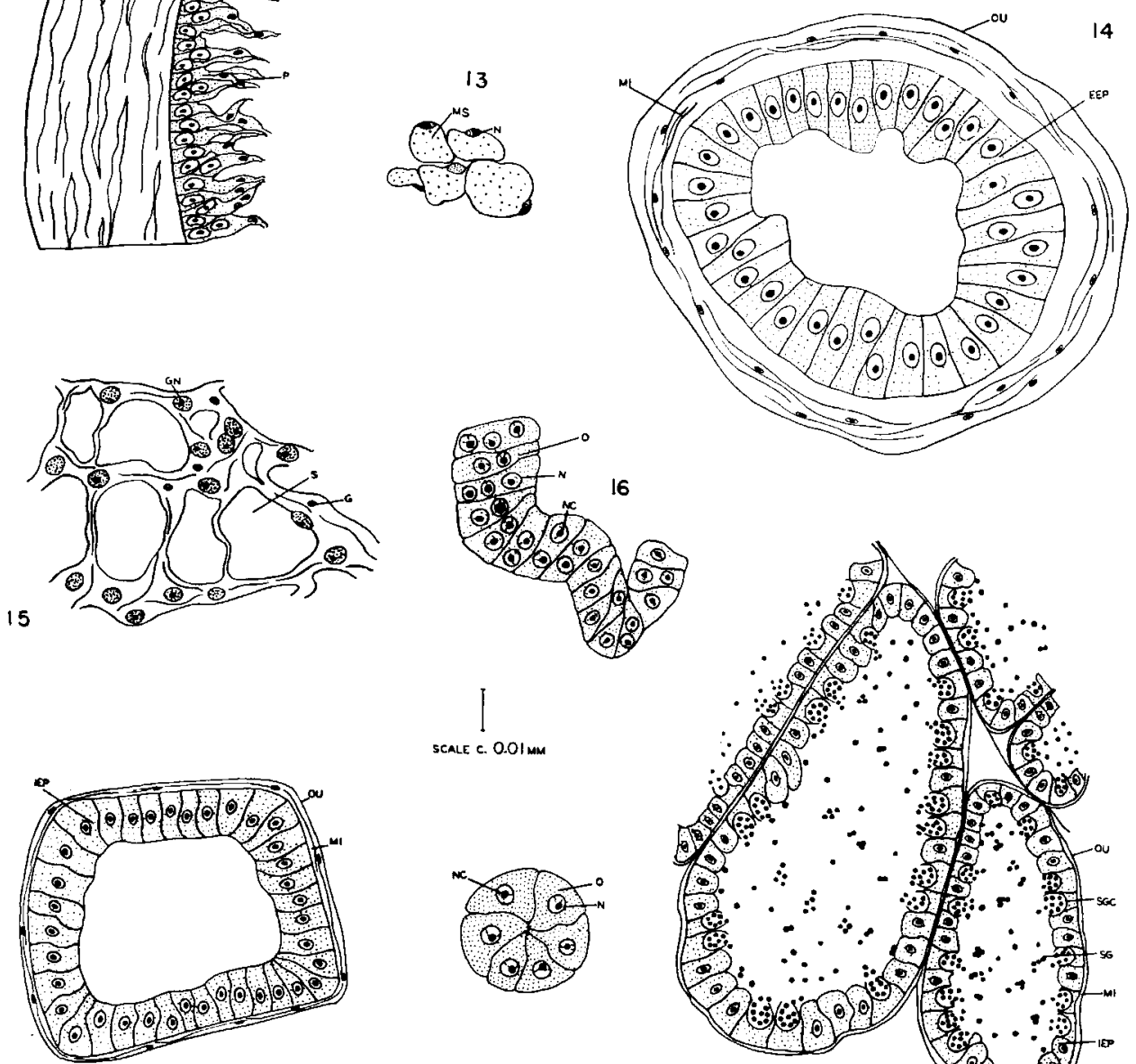

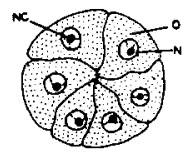

18

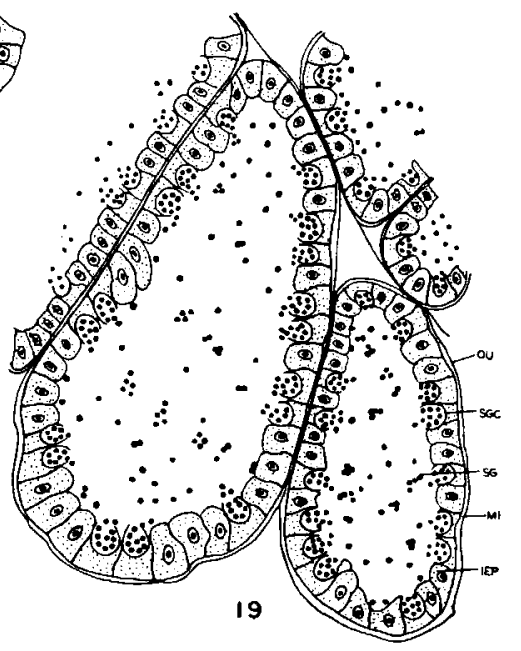




\section{PLATE 4}

EXPLANATION OF FIGURES

20 Portion of cross section through convolutions of oviduet. Seale $A$.

21 Cross section through a single unit of the posterior process. Seale $A$.

22 Cross section through cement gland. Scale A.

23 Cross section through mouth tube. Scale C.

24 Cross seetion through a single ovisac. Seale A.

25 Cross section throngh a single lateral expansion of the cephalothorax. Scale A.

26 Cross section through stomach. Scale A.

27 Cross section through esophagus showing dorsal and ventral sinuses. Scale A.

C, Sclerotized onter layer I)S, Dorsal sinus

HP, Epithelium

FS, Fiber strand

ME, Mouth tube epithelium

IM, Middle layer of ovisae wall

I.X, Inner layer of cement gland

INT, Inner layer of ovisae wall

L, Lamella of outer body wall

M, Middle museular layer

OU, Outer layer of cement gland

OUB, Outer layer of body wall
OUT, Outer membrane

OV, Ovum

OVI, Oviduct

$P$, Parenehyma

$S$, Sinus

SCL, Secreted cement layer

SEP, Stomach epithelium

SG, Secretory granule

SGC, Seeretory gland cell

TOU, Outer layer of ovisac wall

$\mathrm{V}$, Vacuole

VS, Ventral sinus 

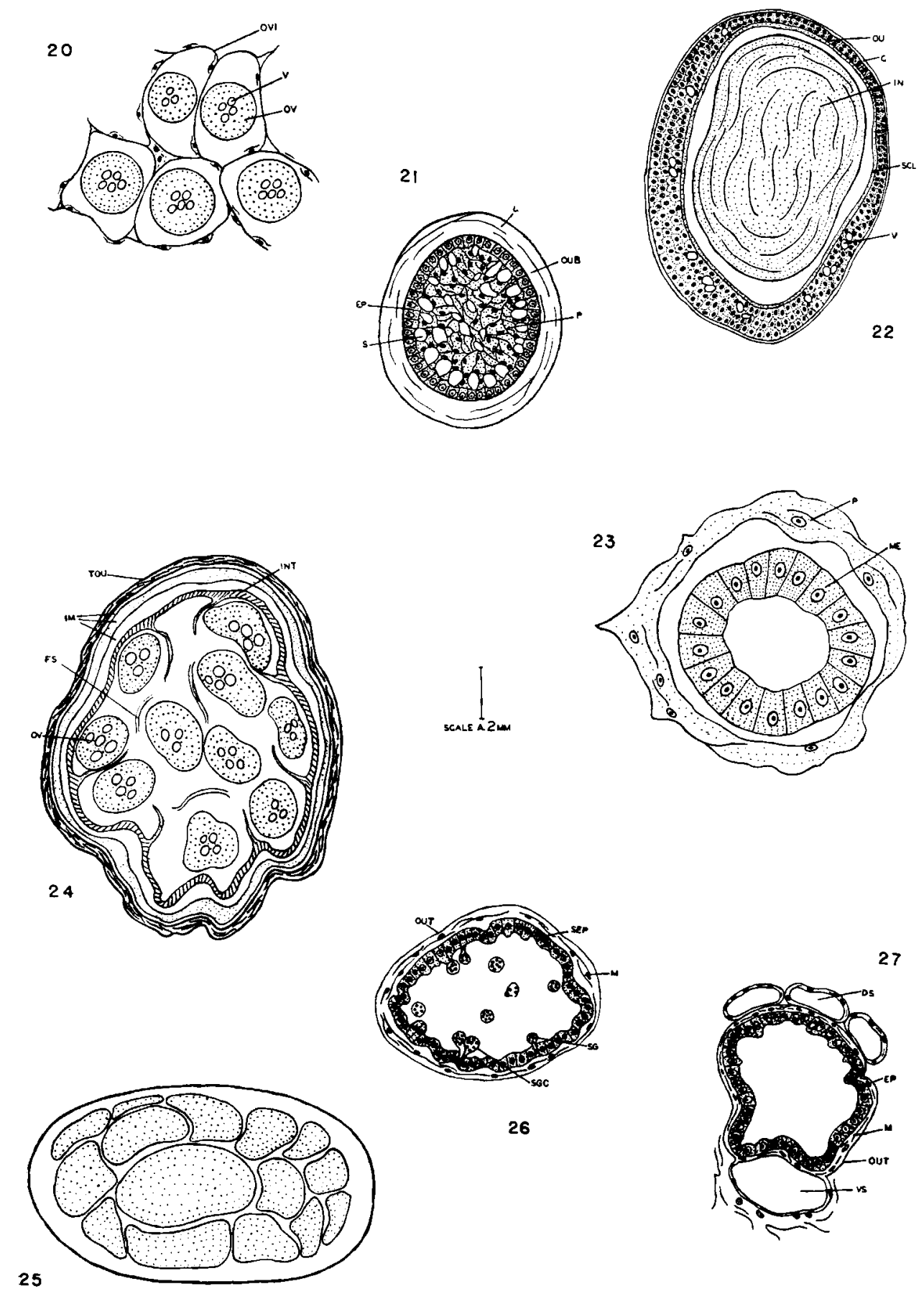